\title{
Traumatic brain injury - the effects of patient age on treatment intensity and mortality
}

\author{
Ola Skaansar ${ }^{1 *}$, Cathrine Tverdal ${ }^{1,2}$, Pål Andre Rønning ${ }^{2}$, Karoline Skogen ${ }^{3}$, Tor Brommeland ${ }^{2}$, Olav Røise ${ }^{1,4}$,
} Mads Aarhus ${ }^{2}$, Nada Andelic ${ }^{5,6}$ and Eirik Helseth ${ }^{1,2}$

\begin{abstract}
Background: Ageing is associated with worse treatment outcome after traumatic brain injury (TBI). This association may lead to a self-fulfilling prophecy that affects treatment efficacy. The aim of the current study was to evaluate the role of treatment bias in patient outcomes by studying the intensity of diagnostic procedures, treatment, and overall 30-day mortality in different age groups of patients with TBI.

Methods: Included in this study was consecutively admitted patients with TBI, aged $\geq 15$ years, with a cerebral CT showing intracranial signs of trauma, during the time-period between 2015-2018. Data were extracted from our prospective quality control registry for admitted TBI patients. As a measure of management intensity in different age groups, we made a composite score, where placement of intracranial pressure monitor, ventilator treatment, and evacuation of intracranial mass lesion each gave one point. Uni- and multivariate survival analyses were performed using logistic multinomial regression.

Results: A total of 1,571 patients with TBI fulfilled the inclusion criteria. The median age was 58 years (range 15-98), $70 \%$ were men, and 39\% were $\geq 65$ years. Head injury severity was mild in 706 patients (45\%), moderate in 437 (28\%), and severe in 428 (27\%). Increasing age was associated with less management intensity, as measured using the composite score, irrespective of head injury severity. Multivariate analyses showed that the following parameters had a significant association with an increased risk of death within 30 days of trauma: increasing age, severe comorbidities, severe TBI, Rotterdam CT-score $\geq 3$, and low management intensity.

Conclusion: The present study indicates that the management intensity of hospitalised patients with TBI decreased with advanced age and that low management intensity was associated with an increased risk of 30-day mortality. This suggests that the high mortality among elderly TBI patients may have an element of treatment bias and could in the future be limited with a more aggressive management regime.
\end{abstract}

Keywords: Traumatic brain injury, Neurosurgery, Age, Treatment, Mortality, Management intensity

\footnotetext{
* Correspondence: o.f.skaansar@studmed.uio.no

${ }^{1}$ Institute of Clinical Medicine, University of Oslo, Oslo, Norway

Full list of author information is available at the end of the article
} 


\section{Background}

Traumatic brain injury (TBI) is a serious public health and societal problem and a major cause of injury-related deaths and disability [1-3]. In the last decades, the typical patient with TBI has changed from a young male, injured in a high-energy trauma, to an elderly man or woman, often with significant comorbidity, injured in a low-energy fall [2-4]. Elderly patients with TBI tend to have a higher initial Glasgow Coma Scale score (GCS) than young patients, and they are less frequently multitraumatised $[2,3,5,6]$. Nevertheless, older age is associated with worse treatment outcome after TBI [7-10]. This may be a direct consequence of biological aging and pre-injury comorbidities [11-14]. However, the association between greater age and poor outcome could also lead to the assumption of futility with regard to immediate thorough diagnostic work-up, neurosurgical procedures, neurointensive treatment, and rehabilitation [15]. Treatment limiting decisions (TLDs) are more often made for older patients with TBI than for the young $[16,17]$. Thus, for some older patients with TBI, limited diagnostic work-up, early TLDs (before $48 \mathrm{~h}$ ), and less rehabilitation may reduce their possibility for survival and recovery. Over time, the high mortality and morbidity among older patients with TBI may start to function as a self-fulfilling prophecy (i.e., a sociological term used to describe a belief that influences people's behaviour in such a way as to align with that belief and fulfil it). In light of recent data indicating the benefit of aggressive treatment and rehabilitation in older patients with TBI [18-23], we evaluated the possibility of a selffulfilling prophecy negatively impacting current TBI treatment regimes and outcomes among older patients.

In this registry study of hospital-admitted TBI patients $\geq 15$ years of age we investigated the potential association between management intensity and risk of 30day mortality in different age groups.

\section{Methods}

\section{Study type}

This is a retrospective study of 1,571 consecutive patients with TBI, aged $\geq 15$ years, treated at the Department of Neurosurgery in Oslo University Hospital $(\mathrm{OUH})$ as inpatients in the acute phase, in a four year time period between 2015-2018.

\section{Study setting}

OUH is the only Level I trauma centre and the only hospital with neurosurgical service in the South-East region of Norway, which had a population of 3.0 million in 2018 [24]. There are 19 local hospitals in this region that are involved in primary care of trauma patients. Trauma patients with severe injuries and patients with suspected severe TBI are admitted directly to OUH. Patients with less severe injuries are admitted to local hospitals but transferred to OUH if in need of neurosurgical surveillance and/or neurosurgical procedures. OUH also serves as the primary trauma referral hospital for Oslo, the population of which was 673,469 in 2018 [24]. Treatment of TBI at OUH follows guidelines made by the Brain Trauma Foundation and the Scandinavian Neurotrauma Committee [25, 26].

\section{Study database}

The Oslo TBI Registry-Neurosurgery is a prospective quality control database run by the neurosurgical department at OUH since January 1, 2015. Data is derived from electronic medical records and stored in the MedInsight database platform. The registry has been approved by an OUH data protection officer (DPO approval number 2016/17,569). Included in the registry are patients fulfilling the following four criteria: (a) TBI, (b) cerebral-CT/cerebral-CT-Angiography or cerebral$\mathrm{MRI} /$ cerebral-MR-Angiography showing signs of acute trauma (haemorrhage, fracture, traumatic axonal injury, vascular injury), (c) admitted to $\mathrm{OUH}$ as an inpatient within seven days after injury, and (d) having a Norwegian social security number.

\section{Independent variables}

The following data was extracted: date of injury, injury mechanism (fall, motor vehicle, pedestrian, bicycle, sport, violence, self-harm, other), sex, age at time of injury, preinjury need for assistance in daily life (living at home without assistance, living at home with assistance or being institutionalised), pre-injury American Society of Anaesthesiologists score (ASA) [27], multiple trauma (trauma in two or more body regions-yes/no), Glasgow Coma Scale score (GCS - recorded as lowest score documented in a time point between injury and OUH emergency room or intubation) [28], Head Injury Severity Scale (HISS—mild, moderate or severe) [29], pathoanatomic injury description on primary cerebral-CT, Rotterdam CT-score on primary cerebral-CT [30], trauma team activation (TTA) at admittance to $\mathrm{OUH}$, advanced TBI imaging (cerebral-MR, cerebral-CTAngiography/cerebral-CT-Venography, or cerebral-MRAngiography/cerebral-MR-Venography), neurosurgical procedures (invasive intracranial pressure monitoring (ICP), evacuation of intracranial mass lesion, and decompressive craniectomy), ventilator treatment (no/yes), and 30-day mortality.

\section{The dependent variable}

As a measure of management intensity in different age groups, we made a composite score, where placement of ICP-monitor, ventilator treatment, and evacuation of intracranial mass lesion each gave one point. Thus, the score for treatment intensity ranged from 0 to 3 . 


\section{Ethics}

This study was approved by the OUH DPO (approval number 2017/3904). The study has been presented to the Regional Ethical Committee (REC). REC categorised the study as a Quality Control Study and determined that DPO approval was sufficient.

\section{Statistics}

Descriptive statistics summarise the characteristics of patients, injuries, and treatment. Categorical data are presented as frequencies and percentages. Continuous variables are presented using mean or median, depending on the distribution. To compare group differences, we used the Pearson $\chi^{2}$ test for categorical variables and independent t-test or Mann-Whitney U-Test for continuous variables. The effect of age on the ordinal variable of treatment intensity was investigated using multivariate ordinal regression. The proportional odds assumption was not fulfilled; instead, a multinomial regression was fitted. To ease the interpretation of the model (available upon request), the calculated probabilities from the model are displayed in a graph. A stratified density plot was created in order to verify that the multinomial model is in line with the observed probabilities. Uni- and multivariate logistic regression was used to investigate the effect on 30-day mortality. An overall survival (OS) analysis was conducted using Kaplan-Meier curves, measuring survival from time of injury to time of death.

$\mathrm{R}$ v3.6 and STATA SE were used for all analyses. $P$ values $<0.05$ were considered significant.

\section{Results}

Patients

Included in this study were 1,571 consecutive adult patients with TBI (aged $\geq 15$ years) and with a cerebral CT showing signs of trauma. Patient characteristics are presented in Table 1. Seventy per cent of the patients were men. The male preponderance was clear in patients aged 15-74 years, while among patients aged 75 years or older there was a gradual shift to a female preponderance. The median age was 58 years (range 15-98). The fractions of patients aged 65 years or older, 75 years or older, and 85 years or older were $39 \%, 20 \%$, and $8 \%$, respectively.

Increasing age was significantly associated with a higher comorbidity (ASA score $3-4) \quad(p<0.001)$, need for assistance in daily life $(p<0.001)$, and the use of antithrombotic medication $(p<0.001)$. Falls were the most frequent injury mechanism (55\%), followed by motor vehicle accidents (10\%), sports accidents (including bicycles) (9\%), and violence/self-harm (10\%). The proportion of fall-related injuries increased significantly with increasing age $(p<0.001)$ (Fig. 1$)$.

\section{Head injury severity}

Mean GCS score, HISS severity grade, and Rotterdam CT-score for the different age groups are presented in Table 1. The mean GCS score and the fraction of mild TBI increased with increasing age $(p<0.03)$, indicating less severe TBI with increasing age. In contrast, the Rotterdam CT-score showed a gradual increase with increasing age, indicating more severe injury in the higher age groups $(p<0.001)$. The fraction of patients with multiple trauma decreased with increasing age $(p<0.001)$.

\section{Patient management}

The trauma team was activated for initial triage in $77 \%$ of the patients, advanced TBI imaging was performed in $60 \%$, ICP-monitoring was used in $24 \%$, ventilator treatment was applied to $41 \%$, surgical evacuation of intracranial mass lesion was done in $14 \%$, and decompressive craniectomy was performed in $2 \%$ (Table 1 ).

Trauma team activation, advanced TBI imaging, invasive ICP monitoring, and ventilator treatment all declined significantly with increasing age $(p<0.001)$. There was no significant change in the rate of surgery with increasing age for mild and moderate TBI, but for severe TBI the age curve was parabola shaped, indicating a low rate of surgery in both young and elderly patients compared to the middle-aged patient group. Decompressive craniectomy was not performed in any patients $\geq$ 75 years. Figure 2 shows the effect of age on the management intensity (composite score). The graphs demonstrate that increasing age is associated with lower management intensity irrespective of head injury severity.

\section{Mortality}

Overall survival analyses were conducted using KaplanMeier curves (Fig. 3). 30-day overall mortality was $12 \%$. 30 -day mortality in the age groups $15-54$ years, 5564 years, 65-74 years, 75-84 years and $\geq 85$ years was $6 \%, 11 \%, 11 \%, 23 \%$ and $24 \%$, respectively. Uni- and multivariate survival analyses were performed using logistic multinomial regression (Table 2 ). In the multivariate analyses, the following parameters had a significant association with an increased risk of death within 30 days of trauma: increasing age, severe comorbidities, severe TBI, Rotterdam CT-score $\geq 4$, and low management intensity. Sex was not associated with 30-day survival.

\section{Discussion}

The present study indicates that the management intensity of hospitalised patients with TBI decreased with advanced age and that low management intensity was associated with an increased risk of 30-day mortality. Thus, we cannot rule out that the higher mortality 
Table 1 Baseline patient characteristics for 1,571 patients by age groups

\begin{tabular}{|c|c|c|c|c|c|c|c|c|}
\hline & $15-24 y r s$ & 25-34yrs & $35-44 y r s$ & $45-54 y r s$ & $55-64 y r s$ & $65-74 y r s$ & 75-84yrs & $\geq 85 \mathrm{yrs}$ \\
\hline Count (n, \%) & $179(100)$ & $168(100)$ & $153(100)$ & $197(100)$ & $258(100)$ & $297(100)$ & $197(100)$ & $122(100$ \\
\hline Male sex (n, \%) & $134(74.9)$ & $134(79.8)$ & $125(81.7)$ & $145(73.6)$ & $195(75.6)$ & $201(67.7)$ & $112(56.9)$ & $46(37.7)$ \\
\hline \multicolumn{9}{|l|}{ Pre-injury ASA-score (n, \%) } \\
\hline 1 & $165(92.2)$ & $134(79.8)$ & $102(66.7)$ & $114(57.9)$ & $72(27.9)$ & $66(22.2)$ & $18(9.1)$ & $4(3.3)$ \\
\hline 2 & $11(6.1)$ & $26(15.5)$ & $31(20.3)$ & $45(22.8)$ & $88(34.1)$ & $127(42.8)$ & $86(43.7)$ & $30(24.6)$ \\
\hline 3 & $3(1.7)$ & $7(4.2)$ & $20(13.1)$ & $38(19.3)$ & $97(37.6)$ & $97(32.7)$ & $91(46.2)$ & $85(69.7)$ \\
\hline 4 & $0(0)$ & $1(0.6)$ & $0(0)$ & $0(0)$ & $1(0.4)$ & $7(2.4)$ & $2(1.0)$ & $3(2.5)$ \\
\hline \multicolumn{9}{|l|}{ Pre-injury living (n, \%) } \\
\hline Independent & $176(98.3)$ & $162(96.4)$ & $147(96.1)$ & $185(93.9)$ & $236(91.5)$ & $269(90.6)$ & $155(78.7)$ & $51(41.8)$ \\
\hline Home with assistance & $1(0.6)$ & $5(3.0)$ & $4(2.6)$ & $8(4.1)$ & $20(7.8)$ & $22(7.4)$ & $29(14.7)$ & $54(44.3)$ \\
\hline Institutionalised & $2(1.1)$ & $1(0.6)$ & $2(1.3)$ & $4(2.0)$ & $2(0.8)$ & $6(2.0)$ & $13(6.6)$ & $17(13.9)$ \\
\hline \multicolumn{9}{|l|}{ Pre-injury antithrombotics (n, \%) } \\
\hline Anticoagulation & $1(0.6)$ & $0(0)$ & $5(3.3)$ & $2(1.0)$ & $14(5.4)$ & $33(11.1)$ & $52(26.4)$ & $38(31.1)$ \\
\hline Platelet inhibitor & $0(0)$ & $0(0)$ & $1(0.7)$ & $10(5.1)$ & $38(14.7)$ & $87(29.3)$ & $68(34.5)$ & $45(36.9)$ \\
\hline $\begin{array}{l}\text { Platelet inhibitor }+ \\
\text { anticoagulation }\end{array}$ & $0(0)$ & $0(0)$ & $1(0.7)$ & $1(0.5)$ & $3(1.2)$ & $7(2.4)$ & $7(3.6)$ & $2(1.6)$ \\
\hline GCS (mean) & 10.0 & 11.0 & 11.1 & 11.0 & 11.2 & 11.8 & 11.4 & 12.5 \\
\hline \multicolumn{9}{|l|}{ HISS (n, \%) } \\
\hline Mild & $62(34.6)$ & $83(49.4)$ & $68(44.4)$ & $81(41.1)$ & $111(43.0)$ & $134(45.1)$ & $94(47.7)$ & $73(59.8)$ \\
\hline Moderate & $50(27.9)$ & $32(19.0)$ & $41(26.8)$ & $58(29.4)$ & $74(28.7)$ & $100(33.7)$ & $50(25.4)$ & $32(26.2)$ \\
\hline Severe & $67(37.4)$ & $53(31.5)$ & $44(28.8)$ & $58(29.4)$ & $73(28.3)$ & $63(21.2)$ & $53(26.9)$ & $17(13.9)$ \\
\hline \multicolumn{9}{|l|}{ Pathoanatomy (n, \%) } \\
\hline Skull fracture & $121(67.6)$ & $107(63.7)$ & $95(62.1)$ & $125(63.5)$ & $135(52.3)$ & $133(44.8)$ & $56(28.4)$ & $36(29.5)$ \\
\hline $\mathrm{SDH}$ & $72(40.2)$ & $73(43.5)$ & $65(42.5)$ & $109(55.3)$ & $169(65.5)$ & $192(64.6)$ & $133(67.5)$ & $77(63.1)$ \\
\hline $\mathrm{tSAH}$ & $80(44.7)$ & $104(61.9)$ & $93(60.8)$ & $116(58.9)$ & $170(65.9)$ & $189(63.6)$ & $118(59.9)$ & $72(59.0)$ \\
\hline $\mathrm{EDH}$ & $47(26.3)$ & $35(20.8)$ & $34(22.2)$ & $36(18.3)$ & $33(12.8)$ & $28(9.4)$ & $9(4.6)$ & $5(4.1)$ \\
\hline Brain contusion & $100(55.8)$ & $82(48.8)$ & $82(53.6)$ & $102(51.8)$ & $138(53.5)$ & $137(46.1)$ & $87(44.2)$ & $48(39.3)$ \\
\hline \multicolumn{9}{|l|}{ Rotterdam CT score (n, \%) } \\
\hline 1,2 & $103(57.5)$ & $82(48.8)$ & $60(39.2)$ & 76 (38.6) & $83(32.2)$ & $89(30.0)$ & $44(22.3)$ & $38(31.1)$ \\
\hline 3,4 & $66(36.9)$ & $67(39.9)$ & $80(52.3)$ & $101(51.3)$ & $152(58.9)$ & $182(61.3)$ & $132(67.0)$ & $73(59.8)$ \\
\hline 5,6 & $10(5.6)$ & 19 (11.3) & $13(8.5)$ & $20(10.2)$ & $23(8.9)$ & $26(8.8)$ & $21(10.7)$ & $11(9.0)$ \\
\hline \multicolumn{9}{|l|}{ Multiple trauma (n, \%) } \\
\hline Yes & $101(56.4)$ & $94(56.0)$ & $78(51.0)$ & $122(61.9)$ & $134(51.9)$ & $127(42.8)$ & 76 (38.6) & $40(32.8)$ \\
\hline No & 78 (43.6) & $74(44.0)$ & $75(49.0)$ & $75(38.1)$ & $124(48.1)$ & $170(57.2)$ & $121(61.4)$ & $82(67.2)$ \\
\hline \multicolumn{9}{|l|}{ Management intensity ( $\mathrm{n}, \%)$} \\
\hline TTA & $165(92.2)$ & $140(83.3)$ & $129(84.3)$ & $167(84.8)$ & $214(82.9)$ & $205(69.0)$ & $127(64.5)$ & $69(56.6)$ \\
\hline CTA/CTV/MRA/MRV & $112(62.6)$ & $97(57.7)$ & $84(54.9)$ & $123(62.4)$ & $164(63.6)$ & $163(54.9)$ & $84(42.6)$ & $21(17.2)$ \\
\hline $\mathrm{MR}$ & $90(50.3)$ & $52(31.0)$ & $52(34.0)$ & $69(35.0)$ & $75(29.1)$ & $50(16.8)$ & $21(10.7)$ & $4(3.3)$ \\
\hline Ventilator therapy & $97(54.2)$ & $69(41.1)$ & $65(42.5)$ & $89(45.2)$ & $119(46.1)$ & $112(37.7)$ & $69(35.0)$ & $22(18.0)$ \\
\hline ICP-monitor & $62(34.6)$ & $40(23.8)$ & $42(27.5)$ & $59(29.9)$ & $81(31.4)$ & $59(19.9)$ & $27(13.7)$ & $3(2.5)$ \\
\hline Evacuation of mass lesion & $18(10.1)$ & $22(13.1)$ & $27(17.6)$ & $27(13.7)$ & $43(16.7)$ & $49(16.5)$ & $20(10.2)$ & $10(8.2)$ \\
\hline Decompressive craniectomy & $4(2.2)$ & $4(2.4)$ & $6(3.9)$ & $9(4.6)$ & $4(1.6)$ & $4(1.3)$ & $0(0)$ & $0(0)$ \\
\hline
\end{tabular}

ASA American Society of Anesthesiologists, LOC Loss of consciousness, GCS Glasgow Coma Scale, HISS Head Injury Severity Scale, SDH Subdural haematoma, tSAH Traumatic subarachnoidal haemorrhage, EDH Epidural haematoma, TTA Trauma team activation, CTA Computed tomography angiography, CTV Computed tomography venography, MRA Magnetic resonance angiography, MRV Magnetic resonance venography, MR Magnetic resonance, ICP Intracranial pressure monitor 


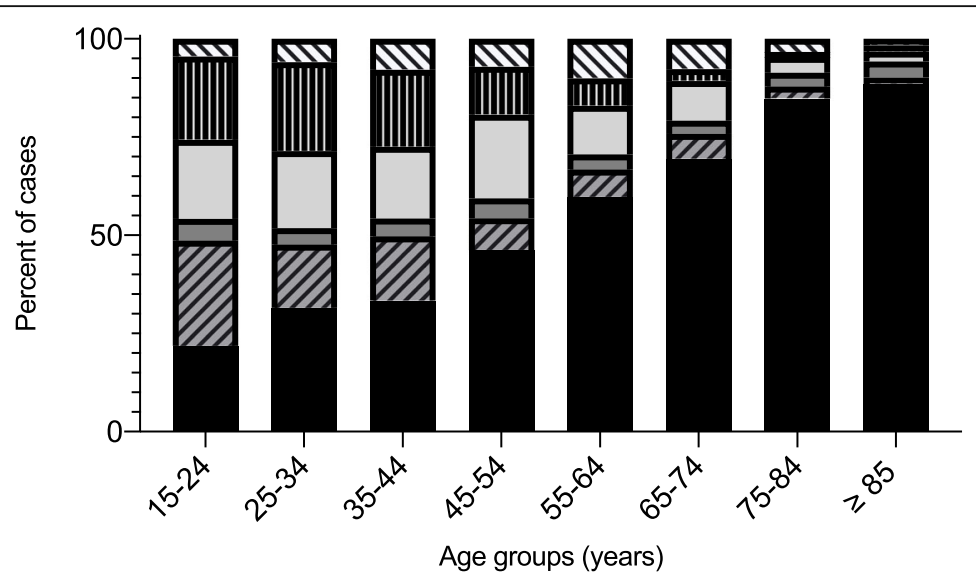

- Fall $\square$ Car \& motorcycle $\square$ Pedestrian $\boldsymbol{\nabla}$ Other

$\square$ Sport (including bike) IIII Violence and self harm

Fig. 1 Injury mechanism in different age groups

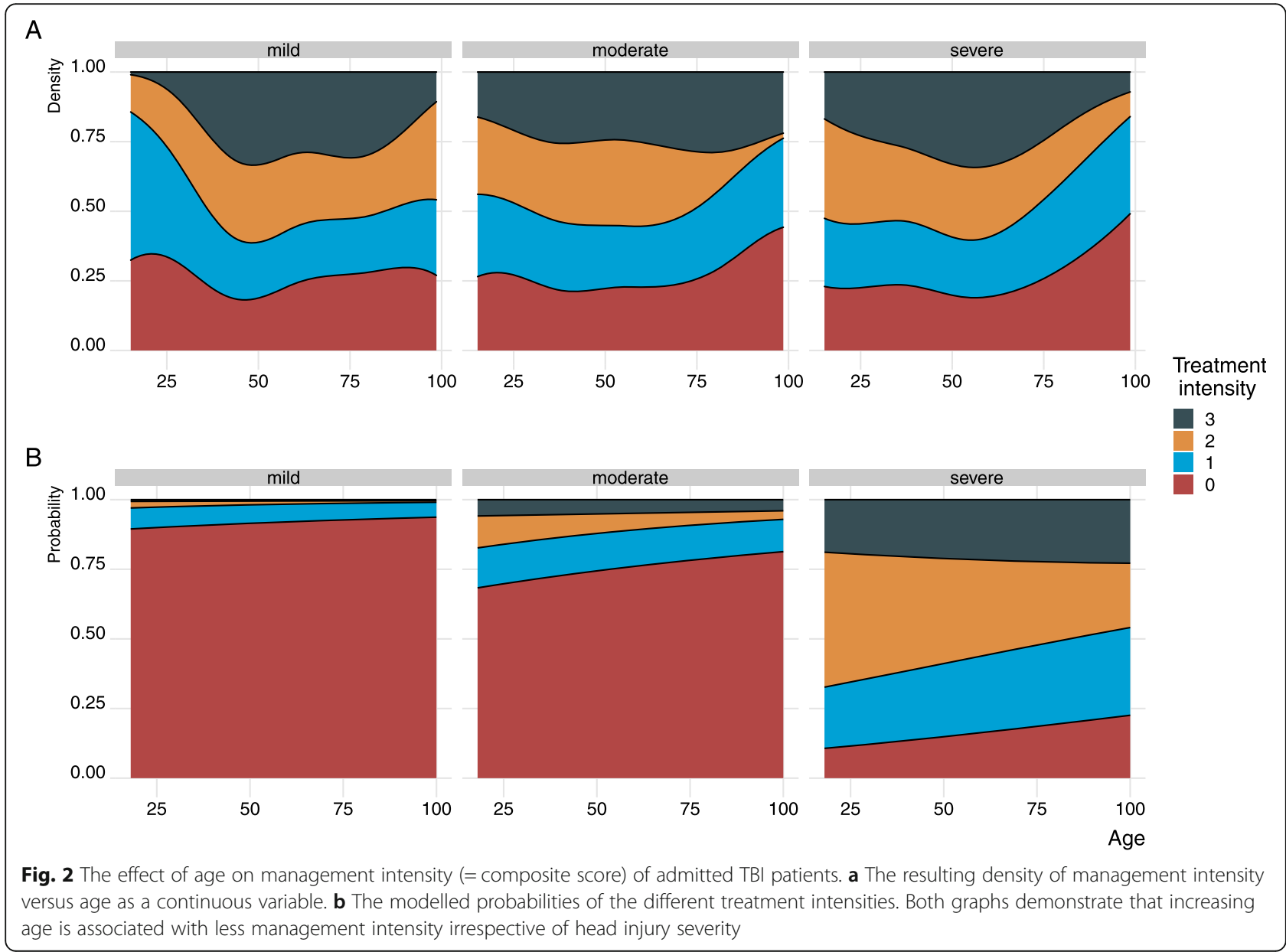




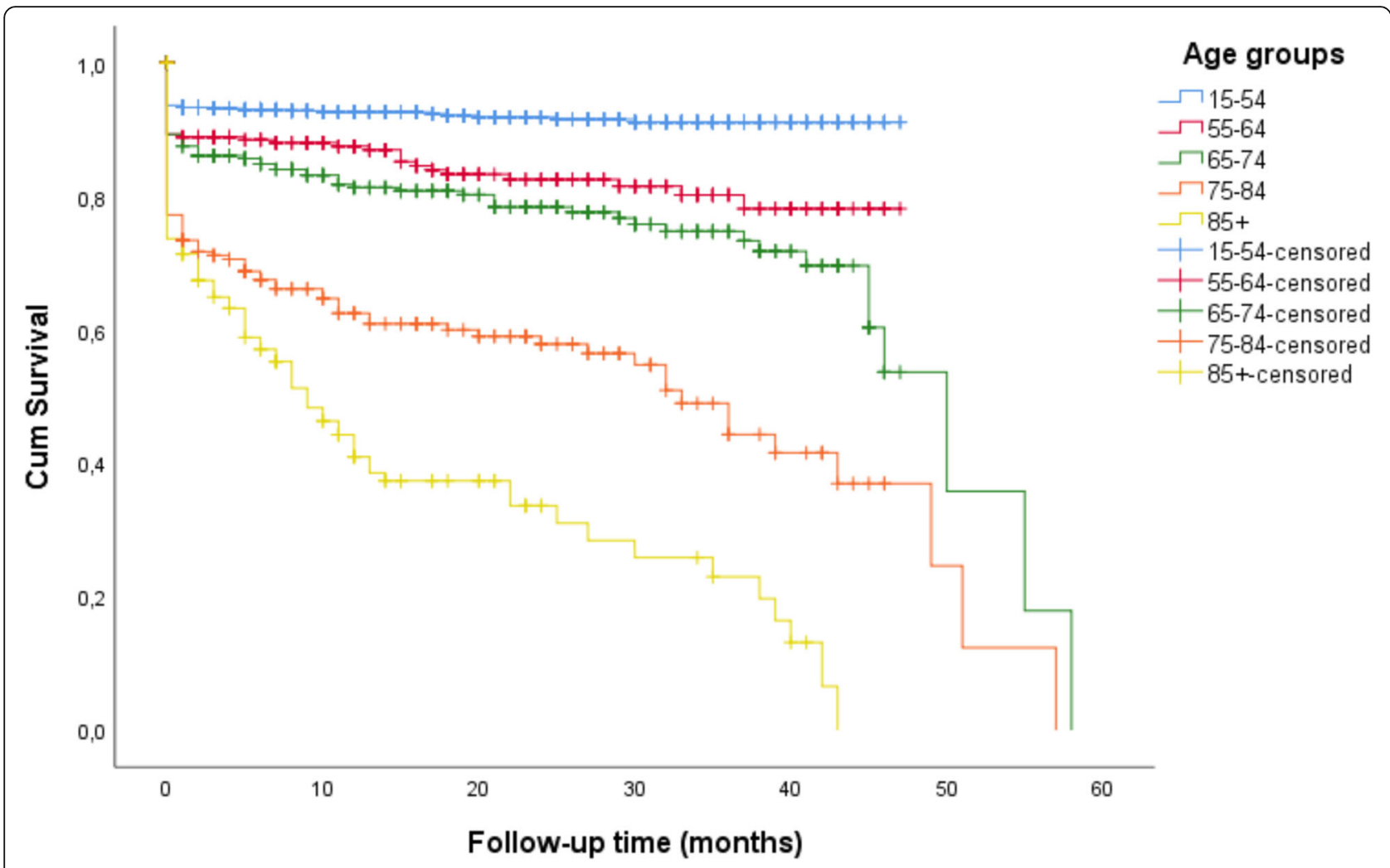

Fig. 3 Kaplan Meyer plot of overall survival after TBI. The plot is showing poorer survival rate with increasing age of the patient

among elderly TBI-patients has an element of selffulfilling prophecy.

\section{Age and sex}

Seventy per cent of our patients were men. The male preponderance was very clear in younger patients, while in older patients this difference was less pronounced. In patients $\geq 85$ years there was a female preponderance. The total number of patients with TBI aged $\geq 55$ years exceeded the number of patients $<55$ years. In sum, there are still many young males admitted for TBI, but they are outnumbered by men and women $\geq 55$ years. The age and sex distributions found in this study are in line with several recently published studies $[3,6,31]$.

\section{Age and comorbidities}

In this study, increasing age was significantly associated with severe systemic disease, need for assistance in daily life, and the use of antithrombotic medication. The close association between older age and comorbidity is in line with other recent TBI studies [3, 32, 33]. Antithrombotics are associated with increased risk of intracranial hematoma after blunt head injury, progression of intracranial hematoma, increased morbidity, and mortality in the TBI population [34-37]. Based on observation in clinical practice, comorbidities appear to be a more important factor than age itself for treatment decisions in patients with TBI.

\section{Age and injury mechanism}

Falls were the most frequent injury mechanism, and the proportion of fall-related injuries increased gradually with increasing age, which is in line with other recent TBI studies [3]. Thus, the typical trauma patient today is a man or woman $\geq 50$ years old with a low-energy fall injury. The World Health Organisation has defined risk factors for falls, and these include polypharmacy, comorbidities, age $>80$ years, impaired cognition (especially attention and executive dysfunction), impaired vision, and environmental factors [38, 39].

\section{Age and injury severity}

The severity of TBI, as assessed by GCS and HISS, tended to decrease with increasing age, whereas TBI severity assessed by the Rotterdam CT score showed a gradual increase in severity with increasing age. This discrepancy is somewhat surprising but may perhaps represent known limitations of GCS and HISS (i.e., they are poor discriminators of less severe TBI). However, an increased fraction of less severe TBI in older adults has been reported and been linked to more frequent lowenergy traumas in this age group [3]. This link is 
Table 2 Cox regression analyses of parameters potentially associated with risk of death within 30-days of trauma

\begin{tabular}{|c|c|c|c|c|c|c|}
\hline & \multicolumn{3}{|c|}{ Univariate } & \multicolumn{3}{|c|}{ Multivariate } \\
\hline & OR & $95 \% \mathrm{Cl}$ & $p$-value & OR & $95 \% \mathrm{Cl}$ & $p$-value \\
\hline Age & 1.03 & 1.02 to 1.04 & $<0.001$ & 1.00 & 1.00 to 1.00 & $<0.001$ \\
\hline \multicolumn{7}{|l|}{ Sex } \\
\hline Female & - & - & & - & - & \\
\hline Male & 0.85 & 0.62 to 1.19 & 0.35 & 1.02 & 0.99 to 1.05 & 0.20 \\
\hline \multicolumn{7}{|l|}{ Preinjury ASA } \\
\hline Healthy & - & - & & - & - & \\
\hline Moderate disease & 1.58 & 1.02 to 2.43 & 0.038 & 0.99 & 0.96 to 1.03 & 0.75 \\
\hline Severe disease & 3.57 & 2.45 to 5.27 & $<0.001$ & 1.06 & 1.02 to 1.10 & 0.004 \\
\hline Life-threatening & 3.82 & 0.84 to 12.8 & 0.045 & 1.09 & 0.95 to 1.25 & 0.20 \\
\hline \multicolumn{7}{|c|}{ Management intensity } \\
\hline 0 & - & - & & - & - & \\
\hline 1 & 8.82 & 5.93 to 13.3 & $<0.001$ & 1.06 & 1.02 to 1.10 & 0.005 \\
\hline 2 & 2.79 & 1.71 to 4.50 & $<0.001$ & 0.91 & 0.87 to 0.95 & $<0.001$ \\
\hline 3 & 4.60 & 2.74 to 7.62 & $<0.001$ & 0.82 & 0.77 to 0.87 & $<0.001$ \\
\hline \multicolumn{7}{|l|}{ TBI severity } \\
\hline Mild & - & - & & - & - & \\
\hline Moderate & 3.77 & 1.57 to 11.2 & 0.007 & 1.03 & 0.99 to 1.06 & 0.11 \\
\hline Severe & 30.4 & 13.7 to 86.4 & $<0.001$ & 1.23 & 1.17 to 1.28 & $<0.001$ \\
\hline \multicolumn{7}{|l|}{ Rotterdam CT score } \\
\hline 1,2 & - & - & & - & - & \\
\hline 3 & 2.00 & 1.17 to 3.53 & 0.013 & 1.00 & 0.97 to 1.03 & 0.85 \\
\hline 4 & 9.16 & 5.05 to 17.1 & $<0.001$ & 1.19 & 1.13 to 1.26 & $<0.001$ \\
\hline 5 & 28.0 & 15.5 to 52.5 & $<0.001$ & 1.48 & 1.39 to 1.57 & $<0.001$ \\
\hline 6 & 111 & 50.1 to 268 & $<0.001$ & 1.86 & 1.71 to 2.02 & $<0.001$ \\
\hline
\end{tabular}

supported by the lower number of multiple traumas that we found among the older adults in our study [3].

\section{Age and management intensity}

As markers for management intensity in the different age groups, we used rates of trauma team activation, advanced TBI imaging, invasive ICP-monitoring, ventilator treatment, surgical evacuation of mass lesion, and decompressive craniectomy. All six parameters showed a declining rate of administration with increasing patient age. Invasive ICP-monitoring, ventilator treatment, and surgical evacuation of mass lesion are directly treatment related, and were included in the composite score of management intensity. The composite score, as visualised in Fig. 2, demonstrates that increasing age was associated with reduced management intensity irrespective of head injury severity. Decompressive craniectomy was not included in the composite score, because it must still be regarded as a treatment with limited documented benefit and is a treatment hardly documented at all in patients $\geq 65$ years $[40,41]$.
Invasive ICP-monitoring of patients with TBI, according to the recommendations by the Brain Trauma Foundation, has been proven beneficial [42]. The reduced use of ICP-monitoring with increasing age has been reported before $[10,42]$, and a low rate of surgical evacuation of traumatic intracranial mass lesions in TBI patients $\geq 65$ years is in line with previous reports [10, 43]. Bus et al. suggested that the tendency to restrict surgical treatment in the elderly is because of presumed poor prognosis and may have acted as a self-fulfilling prophecy [43]. Whitmore and colleagues wrote in 2012: "When all the costs of severe TBI are considered, aggressive treatment is a cost-effective option, even for older patients. Comfort care for severe TBI is associated with poor outcomes and high costs, and should be reserved for situations in which aggressive approaches have failed or testing suggests such treatment is futile" [21]. Kirkman et al. published a study in 2013 on TBI in the elderly and presented national data from UK hospitals showing that time from admission to CT head imaging increased with increasing age, as did the likelihood of not being 
transferred to a centre with acute neurosurgical care facilities and being reviewed only by the most junior grade doctor.

\section{Age and mortality}

The 30-day mortality in this cohort of hospital-admitted patients with TBI identified by neuroimaging was $12 \%$. In multivariate analyses, increasing age, severe comorbidities, increasing severity of head injury, and low management intensity were significantly associated with increased risk of 30-day mortality. These predictors of TBI mortality are in line with other TBI studies [30, 4448]. The associations between age, management intensity and mortality are intriguing and should be assessed in more detail in future studies, especially because the severity of TBIs tends to be lower in elderly patients than younger ones.

\section{Self-fulfilling prophecy?}

The two main findings in this study are the reduced management intensity with increasing age and the association between management intensity and risk of 30day mortality. Whether this reduced management intensity in elderly patients represents well-considered treatment-limiting decisions in selected patients or suboptimal treatment remains unanswered. Thus, we cannot rule out the possibility that the high mortality and morbidity among elderly TBI patients might partly be explained by a self-fulfilling prophecy. The answer to this somewhat provocative question may probably be found in large multicentre comparative effectiveness studies like the CENTER-TBI in Europe and TRACKTBI in the US $[49,50]$. There is also a need for more qualitative research addressing decision-making rules for treatment-limiting decisions in TBI patients among physicians, nurses, and other health care providers [51]. During the last 30 years there has been a significant change in attitude to treating older patients for severe medical conditions, e.g. in cardiology, cancer, and degenerative spine conditions [52-55]. Increased knowledge and improvements during the last decades in anaesthesiology, intensive care medicine, neurosurgery, advanced surgical techniques, and rehabilitation give us the opportunity to push the previous limits of TBI treatment [56-59].

\section{Strengths and limitations}

The present study includes hospital-admitted patients with acute TBI identified by neuroimaging. If patients are triaged after recommended guidelines, the vast majority of adult patients with TBI admitted to the hospital will have intracranial injuries identified by neuroimaging [25]. Thus, the patients included in this study will most likely be representative of the majority of Level 1 trauma hospital-admitted patients with TBI.

A substantial number of trauma patients are first triaged at local hospitals in our health region. The referral practice of these patients to the level 1 trauma centre may depend on the age and comorbidities of the patients. Therefore, we have reason to believe that many older adults with comorbidities and severe injuries are never referred. If this is correct, the management intensity of patients with TBI in the upper age groups is even lower than reported in this study.

We present no direct proof that the high mortality among elderly TBI patients can partly be explained by a self-fulfilling prophecy. Nevertheless, we still believe it is appropriate at least to consider this possibility in light of recent data indicating the benefit of aggressive acute treatment and rehabilitation in older patients with TBI [18-23].

\section{Conclusion}

The present study indicates that the management intensity of hospitalised patients with TBI decreased with advanced age and that low management intensity is associated with an increased risk of 30-day mortality. Thus, we cannot rule out that the high mortality among elderly TBI patients could have been limited with a more aggressive management regime.

\section{Abbreviations \\ ASA: American Society of Anaesthesiologists; CT: Computed Tomography; CTA: Computed Tomography Angiography; CTV: Computed Tomography Venography; DPO: Data Protection Officer; GCS: Glasgow Coma Scale; HISS: Head Injury Severity Scale; ICP: Intracranial Pressure Monitoring; MRI: Magnetic Resonance Imaging; MRA: Magnetic Resonance Angiography; MRV: Magnetic Resonance Venography; OS: Overall Survival; OUH: Oslo University Hospital; REC: Regional Ethical Committee; TBI: Traumatic Brain Injury; TTA: Trauma Team Activation; TLD: Treatment Limiting Decisions}

\section{Acknowledgements}

Not applicable.

\section{Authors' contributions}

OFS and EH were responsible for the study design. EH was the main supervisor, and TB was co-supervisor for OFS. Data collection was done by OFS, CT and EH. Data analysis was mainly done by OFS, EH and PR. KS, MA, $\mathrm{OR}$ and NA contributed with substantial language revisions and interpretation of data. All authors read and approved the final manuscript.

\section{Funding}

A scholarship to OFS was given by the Faculty of Medicine at the University of Oslo. The Department of Neurosurgery, OUH provided office space at the hospital from 2017-2020. None of the funders did take any role or had any demands regarding the study design, data collection, analysis or interpretation of the data.

\section{Availability of data and materials}

The datasets generated and/or analyzed during the current study are not publicly available due to the sensitivity of the material, but are available from the corresponding author on reasonable request.

\section{Ethics approval and consent to participate}

The Oslo TBI Registry - Neurosurgery has been approved by the OUH data protection officer (DPO approval number 2016/17569). This study was 
likewise approved by the OUH data protection officer (DPO-approval number 2017/3904). The study has been presented to the Regional Ethical Committee (REC) for South-East Norway. The REC categorised the study as a Quality Control Study and determined that DPO approval was sufficient. Informed consent was not required from either adults or children.

\section{Consent for publication}

Not Applicable.

\section{Competing interests}

The authors declare that they have no competing interests.

\section{Author details}

'Institute of Clinical Medicine, University of Oslo, Oslo, Norway. ${ }^{2}$ Department of Neurosurgery, Oslo University Hospital, Oslo, Norway. ${ }^{3}$ Department of Radiology and Nuclear Medicine, Oslo University Hospital, Oslo, Norway. ${ }^{4}$ Division of Orthopaedic Surgery, Oslo University Hospital, Oslo, Norway. ${ }^{5}$ Department of Physical Medicine and Rehabilitation, Oslo University Hospital, Oslo, Norway. ${ }^{6}$ Research Centre for Habilitation and Rehabilitation Models and Services (CHARM), Faculty of Medicine, Institute of Health and Society, University of Oslo, Oslo, Norway.

\section{Received: 20 August 2020 Accepted: 29 September 2020}

\section{Published online: 17 October 2020}

\section{References}

1. Majdan M, Plancikova D, Brazinova A, et al. Epidemiology of traumatic brain injuries in Europe: a cross-sectional analysis. Lancet Public Health. 2016;1 (2): e76-83.

2. Maas AIR, Menon DK, Adelson PD, et al. Traumatic brain injury: integrated approaches to improve prevention, clinical care, and research. Lancet Neurol. 2017a;16(12):987-1048.

3. Steyerberg EW, Wiegers E, Sewalt C, et al. Case-mix, care pathways, and outcomes in patients with traumatic brain injury in CENTER-TBI: a European prospective, multicentre, longitudinal, cohort study. Lancet Neurol. 2019, 18(10):923-34

4. Roozenbeek B, Maas AIR, Menon DK. Changing patterns in the epidemiology of traumatic brain injury. Nature Reviews Neurology. 2013; 9(4):231-6.

5. Rau CS, Wu SC, Chen YC, et al. Effect of Age on Glasgow Coma Scale in Patients with Moderate and Severe Traumatic Brain Injury: An Approach with Propensity Score-Matched Population. Int J Environ Res Public Health. 2017;14(11):1378.

6. Gardner RC, Dams-O'Connor K, Morrissey MR, et al. Geriatric Traumatic Brain Injury: Epidemiology, Outcomes, Knowledge Gaps, and Future Directions. J Neurotrauma. 2018:35(7):889-906.

7. Karibe H, Hayashi T, Narisawa A, et al. Clinical Characteristics and Outcome in Elderly Patients with Traumatic Brain Injury: For Establishment of Management Strategy. Neurol Med Chir (Tokyo). 2017;57(8):418-25.

8. Siman-Tov M, Radomislensky I, Knoller N, et al. Incidence and injury characteristics of traumatic brain injury: Comparison between children, adults and seniors in Israel. Brain Inj. 2016;30(1):83-9

9. Mclntyre A, Mehta S, Aubut J, et al. Mortality among older adults after a traumatic brain injury: a meta-analysis. Brain Inj. 2013;27(1):31-40.

10. Roe C, Skandsen T, Anke A, et al. Severe traumatic brain injury in Norway: Impact of age on outcome. J Rehabilitation Med. 2013;45:734-40.

11. Gunning-Dixon FM, Brickman AM, Cheng JC, et al. Aging of cerebral white matter: a review of MRI findings. Int J Geriatric Psychiatry. 2009;24(2):109-17.

12. Okazaki T. Hifumi T, Kawakita K et al. Association Between Comorbidities, Nutritional Status, and Anticlotting Drugs and Neurologic Outcomes in Geriatric Patients with Traumatic Brain Injury. World Neurosurg. 2016;93:33640

13. Thompson HJ, Dikmen S, Temkin N. Prevalence of comorbidity and its association with traumatic brain injury and outcomes in older adults. Res Gerontol Nurs. 2012;5(1):17-24

14. Chan V, Mollayeva T, Ottenbacher KJ, et al. Clinical profile and comorbidity of traumatic brain injury among younger and older men and women: a brief research notes. BMC Res Notes. 2017:10(1):371.

15. Kirkman MA, Jenks T, Bouamra O, et al. Increased mortality associated with cerebral contusions following trauma in the elderly: bad patients or bad management? J Neurotrauma. 2013;30(16):1385-90.
16. Robertsen A, Forde R, Skaga NO, et al. Treatment-limiting decisions in patients with severe traumatic brain injury in a Norwegian regional trauma center. Scand J Trauma Resuscitation Emergency Med. 2017; 25(1):44.

17. Jochems D, van Wessem KJP, Houwert RM, et al. Outcome in Patients with Isolated Moderate to Severe Traumatic Brain Injury. Crit Care Res Pract. 2018; 2018:3769418

18. Mak CH, Wong SK, Wong GK, et al. Traumatic Brain Injury in the Elderly: Is it as Bad as we Think? Curr Transl Geriatr Exp Gerontol Rep. 2012:11:171-8.

19. Lilley EJ, Williams KJ, Schneider EB, et al. Intensity of treatment, end-of-life care, and mortality for older patients with severe traumatic brain injury. J Trauma Acute Care Surg. 2016;80(6):998-1004.

20. Taussky $\mathrm{P}$, Hidalgo ET, Landolt $\mathrm{H}$, et al. Age and salvageability: analysis of outcome of patients older than 65 years undergoing craniotomy for acute traumatic subdural hematoma. World Neurosurg. 2012:78(3-4): 306-11

21. Robert GW, Jayesh PT, Grady MS, et al. Is aggressive treatment of traumatic brain injury cost-effective? J Neurosurg JNS. 2012;116(5):1106-13.

22. Roe C, Skandsen T, Manskow U, et al. Mortality and One-Year Functional Outcome in Elderly and Very Old Patients with Severe Traumatic Brain Injuries: Observed and Predicted. Behav Neurol. 2015:2015:845491.

23. Anke A, Andelic N, Skandsen T, et al. Functional Recovery and Life Satisfaction in the First Year After Severe Traumatic Brain Injury: A Prospective Multicenter Study of a Norwegian National Cohort. J Head Trauma Rehabil. 2015;30(4):e38-49.

24. Statistics Norway, Statbank. 01222: Population and changes during the quarter (M) 1997K4 - 2020K1. 2018. https://www.ssb.no/en/statbank/table/ 01222. Accessed January 04.2020

25. Ingebrigtsen T, Romner B, Kock-Jensen C. Scandinavian guidelines for initial management of minimal, mild, and moderate head injuries. Scand Neurotrauma Committee J Trauma. 2000;48(4):760-6.

26. Carney N, Totten AM, O'Reilly C, et al. Guidelines for the Management of Severe Traumatic Brain Injury. Fourth Edition Neurosurg. 2017;80(1):6-15.

27. ASA House of Delegates/Executive Committee. ASA Physical Status Classification System. 2014. https://www.asahq.org/standards-andguidelines/asa-physical-status-classification-system. Accessed 21. Dec.2019.

28. Teasdale G, Jennett B. Assessment of Coma and Impaired Consciousness: A Practical Scale. Lancet. 1974:304(7872):81-4.

29. Stein SC, Spettell C. The Head Injury Severity Scale (HISS): a practical classification of closed-head injury. Brain Inj. 1995;9(5):437-44.

30. Hukkelhoven CW, Steyerberg EW, Rampen AJ, et al. Patient age and outcome following severe traumatic brain injury: an analysis of 5600 patients. J Neurosurg. 2003:99(4):666-73.

31. Peeters W, van den Brande R, Polinder S, et al. Epidemiology of traumatic brain injury in Europe. Acta Neurochir (Wien). 2015;157(10):1683-96.

32. Fu WW, Fu TS, Jing R, et al. Predictors of falls and mortality among elderly adults with traumatic brain injury: A nationwide, population-based study. PLOS ONE. 2017;12(4):e0175868

33. Kumar R, Juengst $\mathrm{S}$, Wang $Z$, et al. Epidemiology of Comorbid Conditions Among Adults 50 Years and Older With Traumatic Brain Injury. J Head Trauma Rehabilitation. 2017:33:1.

34. Scotti P, Seguin C, Lo BWY, et al. Antithrombotic agents and traumatic brain injury in the elderly population: hemorrhage patterns and outcomes. J Neurosurg. 2019;1:1-10.

35. Gulati S, Solheim O, Carlsen SM, et al. Risk of intracranial hemorrhage (RICH) in users of oral antithrombotic drugs: Nationwide pharmacoepidemiological study. PLoS ONE. 2018;13(8):e0202575.

36. Gaist $D$, García Rodríguez LA, Hellfritzsch M, et al. Association of Antithrombotic Drug Use With Subdural Hematoma Risk. JAMA. 2017;317(8): $836-46$.

37. Mathieu F, Zeiler FA, Ercole A, et al. Relationship between measures of cerebrovascular reactivity and intracranial lesion progression in acute TB patients: a CENTER-TBI study. J Neurotrauma. 2020;32(2):373-82.

38. WHO Regional Office for Europe, Copenhagen. What are the Main Risk Factors for Falls Amongst Older People and what are the Most Effective Interventions to Prevent These Falls? 2004. https://www.euro.who.int/ document/E82552.pdf. Accessed 10 Feb.2020.

39. Ambrose AF, Paul G, Hausdorff JM. Risk factors for falls among older adults: a review of the literature. Maturitas. 2013;75(1):51-61.

40. Cooper DJ, Rosenfeld JV Murray L et al. Decompressive Craniectomy in Diffuse Traumatic Brain Injury. N Engl J Med. 2011;364(16):1493-502. 
41. Hutchinson PJ, Kolias AG, Timofeev IS, et al. Trial of Decompressive Craniectomy for Traumatic Intracranial Hypertension. N Engl J Med. 2016; 375(12):1119-30

42. Ronning P, Helseth E, Skaga NO, et al. The effect of ICP monitoring in severe traumatic brain injury: a propensity score-weighted and adjusted regression approach. J Neurosurg. 2018;1:1-9.

43. Bus S, Verbaan D, Kerklaan BJ, et al. Do older patients with acute or subacute subdural hematoma benefit from surgery? Br I Neurosurg. 2019;33(1):51-7.

44. Baum J, Entezami P, Shah $\mathrm{K}$, et al. Predictors of Outcomes in Traumatic Brain Injury. World Neurosurg. 2016;90:525-9.

45. Lew HL, Lee E, Date ES, et al. Influence of medical comorbidities and complications on FIM change and length of stay during inpatient rehabilitation. Am J Phys Med Rehabil. 2002;81(11):830-7.

46. Selassie AW, McCarthy ML, Ferguson PL, et al. Risk of posthospitalization mortality among persons with traumatic brain injury, South Carolina 19992001. J Head Trauma Rehabil. 2005;20(3):257-69.

47. Thompson HJ, Rivara FP, Jurkovich GJ, et al. Evaluation of the effect of intensity of care on mortality after traumatic brain injury. Crit Care Med. 2008;36(1):282-90.

48. Kristman VL, Brison RJ, Bedard M, et al. Prognostic Markers for Poor Recovery After Mild Traumatic Brain Injury in Older Adults: A Pilot Cohort Study. J Head Trauma Rehabil. 2016:31(6):e33-43.

49. Maas Al, Menon DK, Steyerberg EW, et al. Collaborative European NeuroTrauma Effectiveness Research in Traumatic Brain Injury (CENTER-TBI): a prospective longitudinal observational study. Neurosurgery. 2015;76(1):6780.

50. Yue JK, Vassar MJ, Lingsma HF, et al. Transforming research and clinical knowledge in traumatic brain injury pilot: multicenter implementation of the common data elements for traumatic brain injury. J Neurotrauma. 2013; 30(22):1831-44.

51. Robertsen A, Helseth E, Laake JH, et al. Neurocritical care physicians' doubt about whether to withdraw life-sustaining treatment the first days after devastating brain injury: an interview study. Scand I Trauma Resuscitation Emergency Med. 2019;27(1):81

52. Shahrokni A, Kim SJ, Bosl GJ, et al. How We Care for an Older Patient With Cancer. Journal of Oncology Practice. 2017;13(2):95-102.

53. Nicolini F, Agostinelli A, Vezzani A, et al. The evolution of cardiovascular surgery in elderly patient: a review of current options and outcomes. Biomed Res Int. 2014;2014:736298.

54. Lykissas MG, Giannoulis D. Minimally invasive spine surgery for degenerative spine disease and deformity correction: a literature review. Ann Transl Med. 2018;6(6):99.

55. Bernardi $D$, Errante $D$, Bianco A, et al. Treatment of elderly cancer patients: a planet in evolution. J Am Geriatr Soc. 2006;54(2):372-3.

56. Maas AIR, Menon DK, Adelson PD, et al. Traumatic brain injury: integrated approaches to improve prevention, clinical care, and research. Lancet Neurol. 2017b;16(12):987-1048.

57. Maas A. Traumatic brain injury: Changing concepts and approaches. Chin $J$ Traumatol. 2016;19(1):3-6.

58. Xiong Y, Mahmood A, Chopp M. Emerging treatments for traumatic brain injury. Expert Opin Emerg Drugs. 2009;14(1):67-84.

59. Brazinova A, Majdan M, Leitgeb J, et al. Factors that may improve outcomes of early traumatic brain injury care: prospective multicenter study in Austria. Scand J Trauma Resuscitation Emergency Med. 2015;23(1):53.

\section{Publisher's Note}

Springer Nature remains neutral with regard to jurisdictional claims in published maps and institutional affiliations.

Ready to submit your research? Choose BMC and benefit from:

- fast, convenient online submission

- thorough peer review by experienced researchers in your field

- rapid publication on acceptance

- support for research data, including large and complex data types

- gold Open Access which fosters wider collaboration and increased citations

- maximum visibility for your research: over $100 \mathrm{M}$ website views per year

At $\mathrm{BMC}$, research is always in progress.

Learn more biomedcentral.com/submissions 